\title{
Image-guided study of swine anatomy as a tool for urologic surgery research and training ${ }^{1}$
}

Jacob Hindrik Antunes Smit' (iD, Eduardo Piotto Leonardi" (iD, Rosa Helena de Figueiredo Chaves"I (iD, Ismari Perini FurlanetoIv (iD, Cezar Massoud Salame da Silvav (iD, Simone de Campos Vieira Abibvi (iD), Adenauer Marinho de Oliveira Góes Junior ${ }^{\mathrm{VII}}$ iD

' Graduate student, School of Medicine, Centro Universitário do Estado do Pará, Belém-PA, Brazil. Analysis and interpretation of data, manuscript preparation, final approval.

"MSc, Associate Professor, Department of Urology, School of Medicine, Centro Universitário do Estado do Pará, Belém-PA, Brazil. Substantive scientific and intellectual contributions to the study, conception and design, critical revision, final approval.

I'PhD, Grupo de Pesquisa Experimental, Centro Universitário do Estado do Pará, Belém-PA, Brazil. Technical procedures, critical revision.

IVPhD, Grupo de Pesquisa Experimental, Centro Universitário do Estado do Pará, Belém-PA, Brazil. Statistics analysis, critical revision, final approval.

${ }^{\vee}$ MSc, Associate Professor, Department of Radiology, School of Medicine, Centro Universitário do Estado do Pará, Belém-PA, Brazil. Analysis and interpretation of data, critical revision, final approval.

${ }^{V}$ PhD, Associate Professor, Department of Surgery, Universidade Federal de São Paulo-SP, Brazil. Conception and design, critical revision, final approval.

VIIPhD, Full Professor, Department of Vascular Surgery, Grupo de Pesquisa Experimental, Centro Universitário do Estado do Pará, Belém-PA, Brazil. Substantive intellectual and scientific contributions to the study, conception and design, critical revision, final approval.

\begin{abstract}
Purpose: To describe the anatomy of the swine urinary system using computed tomography and to discuss the role of this animal as an experimental model for urological procedures.

Methods: Three male Landrace pigs underwent computed tomography and the anatomy of the urinary system and renal circulation was analyzed and described.

Results: In all animals, 2 kidneys, 2 ureters and one bladder were identified. Each kidney presented a single renal artery vascularization, with a mean diameter on the right of 4.45 and $5.31 \mathrm{~mm}$ on the left $(p<0.0001)$ and single renal vein drainage, with a mean diameter on the right of 5.78 and $5.82 \mathrm{~mm}$ on the left $(p=0.0336)$. The average renal length was $9.85 \mathrm{~cm}$ on the right and $10.30 \mathrm{~cm}$ on the left $(p<0.0001)$. The average renal volume was $113.70 \mathrm{~cm}^{3}$ on the right and $109.70 \mathrm{~cm}^{3}$ on the left $(p<0.0001)$. The average length of the ureter was $19.78 \mathrm{~cm}$ on the right and $22.08 \mathrm{~cm}$ on the left $(p<0.0001)$. The average bladder volume was $423.70 \mathrm{~cm}^{3}$.
\end{abstract}

Conclusion: The data obtained show similarities with human anatomy, suggesting the viability of the swine model for planning preclinical trials, basic research, refinement in experimental surgery and surgical training for urological procedures.

Key words: Urologic Surgical Procedures. Tomography. X-Ray Computed. Anatomy. Swine. 


\section{- Introduction}

Animal models are widely used in experimental research with rats being the main species used in basic research; however, pigs play a prominent role in studies of more complex surgical techniques ${ }^{1,2}$.

Anatomical and physiological similarities of various systems, such as the urinary and circulatory, that exist between pigs and humans, combined with the wide availability and reasonable prices, make these animals a good option for research models and training in surgery ${ }^{3-7}$.

Pigs are used as an experimental model for urological and endourological procedures, such as percutaneous nephrolithotomy ${ }^{8,9}$, percutaneous renal access ${ }^{10}$, ureterocalicostomy (open and laparoscopic) ${ }^{11}$ and kidney transplantation ${ }^{3,12}$.

The literature presents anatomical descriptions of the swine urinary system, addressing the pyelocaliceal system ${ }^{7,13}$, extra and intrarenal vascularization ${ }^{4,5}$, the ureters ${ }^{14}$ and the urethra ${ }^{15}$, as well as studies of comparative anatomy. Most of these descriptions were based on surgical dissection, plastination and invasive exams, such as angiography, with a few studies using more modern noninvasive imaging methods, like multislice computed tomography (CT). Thus, this research aimed to describe the porcine urinary system based on computed tomography images and to discuss similarities and differences to the human anatomy, as well as, based on tomographic findings, to discuss the application of the porcine model in surgical training and research regarding the urinary system.

\section{- Methods}

The study was approved by the institution's ethics committee on the use of animals (CEUA CESUPA 01/2017).

Three Landrace male pigs, weighing 45.4, 49.2 and $52.3 \mathrm{~kg}$, were used for CT imaging. The animals were kept in a standard environment with adequate housing conditions (temperature and humidity control) and fasted for $12 \mathrm{~h}$ before the exam.

\section{Anesthetic protocol}

The CT scans were performed under general anesthesia and monitoring, performed by a veterinarian. As pre-anesthetic medication, a combination of ketamine hydrochloride $(15 \mathrm{mg} / \mathrm{kg}$ ) and xylazine hydrochloride $(1.5 \mathrm{mg} / \mathrm{kg})$ was administered by the intramuscular injection.

Then the marginal vein of the ear was accessed with a peripheral catheter $(22 \mathrm{G})$, through which hydration with a physiological solution and anesthetic induction, using propofol at a dose of $2.5-5 \mathrm{mg} / \mathrm{kg}$, were instituted. The maintenance was performed with the same agent through continuous infusion $(0.1-0.2 \mathrm{mg} / \mathrm{kg} / \mathrm{min})$. After being in the anesthetic plane, the swine was positioned in ventral decubitus for CT image acquisition.

All animals maintained spontaneous respiration, with no need of intubation.

\section{Computed tomography}

The CT scans were performed on a 64-channel tomography with $0.625 \mathrm{~mm}$ cuts. The intravenous iodinated contrast used was iohexol ( $120 \mathrm{~mL}$ at a flow rate of $5 \mathrm{~mL} / \mathrm{s})$.

\section{Image analysis}

Images were evaluated through the software Horos v3.1.0 (Horosproject.org).

For anatomical descriptions, the terms "cranial" and "caudal" were adopted as corresponding to "superior" and "inferior" in humans, respectively.

The following parameters were measured:

Vascular parameters

- Renal artery: diameter of the proximal segment.

- Left renal vein: diameter at the renal hilum and at the point of maximum narrowing between the aorta and the anterior mesenteric artery.

- Right renal vein: diameter at the renal hilum.

Arterial branching pattern was classified accordingly to the types proposed by Evan et al. ${ }^{16}$.

Urinary parameters

- Renal length: the greater distance between the cranial and caudal edges.

- Cranial and caudal pole width: from an axis, perpendicular to the length, drawn in the widest segment of the renal poles (cranial and caudal).

- Kidney hilum angle: determined by the technique proposed by Sakate et al. ${ }^{17}$, comparing the renal hilum pathway to a line drawn by the vertebral body, as shown in Fig. 1.

- Ureteral length: from the ureteropelvic junction to the ureterovesical junction. The external iliac artery was used as a reference point to divide the ureter into abdominal (cranial) and pelvic (caudal) ureteral segments.

- Kidney and bladder volumes: measured using the ROI (region of interest) tool from Horos v3.3.0 software.

The landmarks used to measure the anatomical features can be visualized in Fig. 1. 
(a)

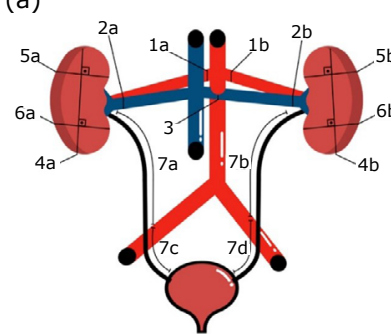

(b)

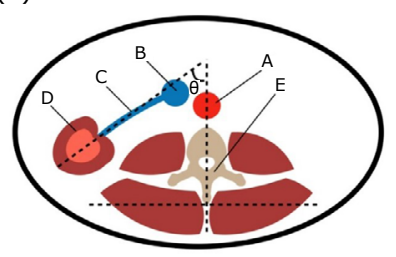

Figure 1 - Anatomical landmarks used for measurement. (a) Vascular diameters: right renal artery (1a), left renal artery (1b), right renal vein (2a), left renal vein on the renal hilum (2b), left renal vein on the maximum point of compression (between the aorta and the anterior mesenteric artery) (3). Urinary measurements: the length between the most cranial and caudal point of the right and left kidneys (4a/4b), the width of the right and left cranial renal poles $(5 a / 5 b)$ and the width of the right and left caudal renal poles $(6 a / 6 b)$, the length of the right and left abdominal ureteral segments $(7 a / 7 b)$, and the right and left pelvic ureteral segments $(7 c / 7 d)$. (b) Angle of the renal hilum: an imaginary line drawn in the center of the vertebral body (E); a virtual line drawn on the path of the renal vein (C) from the kidney (D) to the caudal vena cava (B). abdominal aorta (A).

\section{Statistical analysis}

The analyses were performed using the software's GraphPad Prism v8.4.3 and Bioestat v5.3, considering significant values of $p \leq 0.05$.

From the distributions of $n=3$ observations, an empirical data distribution with 500 observations was independently calculated for each data set using the computational method of data generation (Bioestat) and then, the normality of these distributions was verified using the Shapiro-Wilk test. The mean, standard deviation and coefficient of variation were determined for all data sets and, considering that the distributions were estimated independently, the comparison between them was made by the MannWhitney test.

\section{Results}

Anatomical relations are observed in Fig. 2. In all animals, 2 kidneys, 2 ureters and one bladder were identified. Animal 1 presented a simple renal cyst on the right side.

Each kidney showed a vascularization by a single renal artery emerging from the abdominal aorta near the 2 nd lumbar vertebra, symmetrically (Fig. 3a); except in animal 1 , which had an emission of the right renal artery $8.5 \mathrm{~mm}$ more caudal than the left renal artery. No extra hilar arterial branches were identified. Next to the abdominal aorta, the diameter of the right renal artery varied between 3.50 and $5.14 \mathrm{~mm}$ with a mean of $4.45 \mathrm{~mm}$ and between 5.08 and $5.70 \mathrm{~mm}$ with a mean of $5.31 \mathrm{~mm}$ on the left. The mean diameter was statistically superior on the left renal artery $(p<0.0001)$ (Fig. 3b).

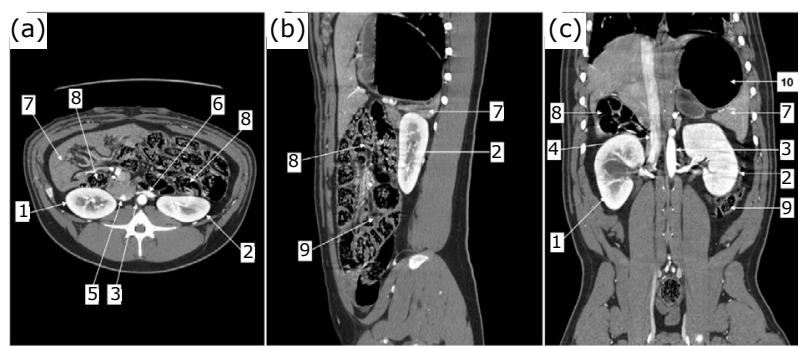

Figure 2 - Computed tomography cuts with intravenous contrast in animal 1 . (a) transversal section; (b) sagittal section; (c) coronal section; 1 : right kidney; 2: left kidney; 3: abdominal aorta; 4: caudal vena cava; 5 : right renal vein; 6: left renal vein; 7: liver; 8: small intestine; 9: large intestine; 10: stomach.
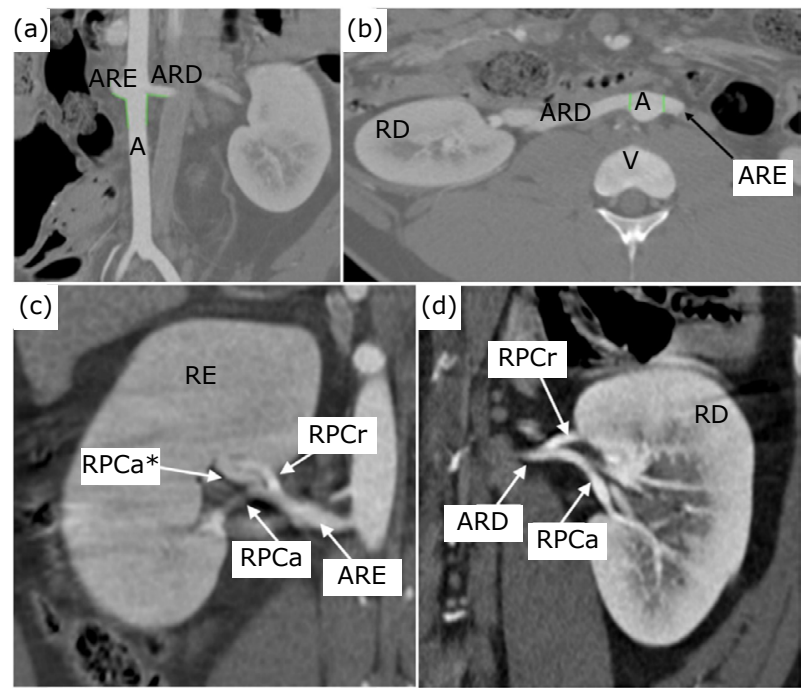

Figure 3 -Computed tomography cuts with intravenous contrast. (a) coronal section in posteroanterior view; (b) axial section; (c) and (d) coronal sections in posteroanterior view (branching pattern of the renal artery, type II and la respectively). A: aorta; ARE: left renal artery; ARD: right renal artery; RD: right kidney; RE: left kidney; V: vertebra; RPCr: cranial pole branch; RPCa: caudal pole branch; RPCa*: vessel emitted from the caudal pole branch to the cranial pole.

The images obtained allowed the identification of the arterial branching pattern in all kidneys, except for the right kidney of animal 1. Based on the classification of Evan et al. ${ }^{16}$, the animals 2 and 3 presented cranial and 
caudal polar branches with a distal bifurcation into anterior and posterior branches, characterized as type la (Fig. 3d). In the left kidney of animal 1, a short cranial polar branch with anterior and posterior branching at the renal artery topography was noticed, associated with the emission of a vessel from the caudal polar branch towards the cranial pole (type II) (Fig. 3c).

Two or three venous tributaries converged to form a single renal vein on each side (Fig. 4A), which flowed into the caudal vena cava between the last thoracic vertebra and the 2 nd lumbar vertebra. Near the renal hilum, the diameter of the renal vein varied between 4.90 and $6.40 \mathrm{~mm}$ on the right, with an average of $5.78 \mathrm{~mm}$ and between 5.26 and $6.35 \mathrm{~mm}$ on the left, with an average of $5.82 \mathrm{~mm}$. The venous diameter measured at the hilum was statistically superior on the left side ( $p=0.0336)$. A narrowing of the left renal vein, between the aorta and the anterior mesenteric artery (analogous to the nutcracker syndrome in humans ${ }^{18}$ ), was observed in all animals (Fig. 4b). At this point, the renal vein diameter average was $2.78 \mathrm{~mm}$.
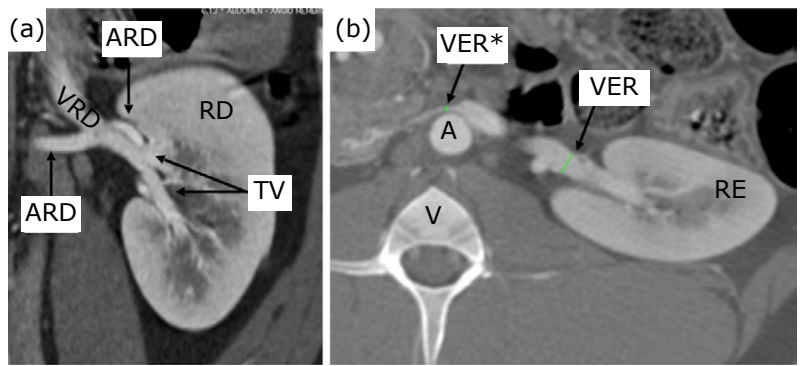

Figure 4 - (a) coronal section in posteroanterior view; (b) axial section; RD: right kidney; $A R D$ : right renal artery; TV: venous tributaries; VRE: left renal vein; VRE*: left renal vein at the maximum point of compression.

A renal cyst equivalent to a Bosniak ${ }^{19}$ lesion was identified in the right kidney of animal 1.

The renal length varied from 9.10 to $10.46 \mathrm{~cm}$ on the right, with an average of $9.85 \mathrm{~cm}$, and from 9.22 to $11.70 \mathrm{~cm}$ on the left, with an average of $10.30 \mathrm{~cm}$. The renal length was statistically superior on the left side $(p<0.0001)$. The width of the cranial renal pole varied between 5.11 and $6.45 \mathrm{~cm}$, with an average of $5.82 \mathrm{~cm}$ on the right, and between 5.65 and $6.57 \mathrm{~cm}$, with an average of $6.05 \mathrm{~cm}$ on the left. The width of the cranial pole was statistically superior on the right side $(p<0.0001)$. The width of the caudal renal pole varied between 4.29 and $5.52 \mathrm{~cm}$, with an average of $4.92 \mathrm{~cm}$ on the right, and between 4.48 and $5.16 \mathrm{~cm}$, with an average of $4.85 \mathrm{~cm}$ on the left, with no statistical difference between the sides ( $p=0.0625$ ) (Fig. 5a).
The renal volume varied between 79.78 and $130.50 \mathrm{~cm}^{3}$ on the right, with an average of $113.70 \mathrm{~cm}^{3}$, and between 78.32 and $125.50 \mathrm{~cm}^{3}$ on the left, with an average of $109.70 \mathrm{~cm}^{3}$. The renal volume was statistically higher on the right side ( $p<0.0001$ ) (Fig. 5b).

The angle of the renal hilum varied between 73.53 and $74.85^{\circ}$ on the right, with an average of $74.08^{\circ}$, and between 63.87 and $70.39^{\circ}$ on the left, with an average of $67.59^{\circ}$. The right renal hilum angulation was statistically superior when compared to the left side $(p<0.0001)$ (Fig. 5c).
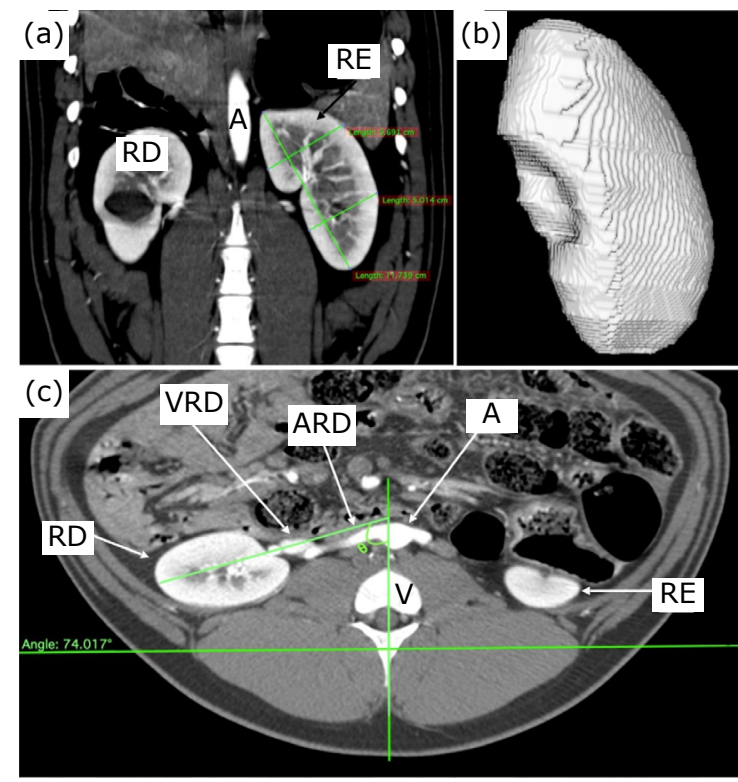

Figure 5 - (a) coronal section in anteroposterior view; (b) $3 \mathrm{D}$ reconstruction of the right kidney;(c): axial section; RE: left kidney; RD: right kidney; A: aorta; V: vertebra; VRD: left renal vein; $A R D$ : right renal artery.

The ureters presented a slight tortuosity along their path. The total length varied between 16.06 and $23.13 \mathrm{~cm}$ on the right, with an average of $19.78 \mathrm{~cm}$, and between 21.55 and $23.21 \mathrm{~cm}$ on the left, with an average of $22.08 \mathrm{~cm}$, the total ureteral length was statistically superior on the left $(p<0.0001)$. On the right side, the abdominal segment of the ureter varied between 12.18 and $15.85 \mathrm{~cm}$ (mean of $13.55 \mathrm{~cm}$ ) and between 13.41 and $17.52 \mathrm{~cm}$ on the left (mean of $15.75 \mathrm{~cm}$ ), and the length of the abdominal segment was statistically superior to the left $(p<0.0001)$. The pelvic segment of the ureter measured between 3.88 and $7.28 \mathrm{~cm}$ on the right (mean of $6.16 \mathrm{~cm}$ ) and between 5.61 and $8.22 \mathrm{~cm}$ on the left (mean of $6.42 \mathrm{~cm}$ ), but no statistical difference was identified between them ( $p=0.9302$ ). A ureteral narrowing was identified when crossing the external iliac artery in all animals. Only in pigs 1 and 3 a 
narrowing at the vesicoureteral junction was detected, both on the left side (Figs. 6a and b).

The bilateral ureteral implantation was observed at the posterior wall of the bladder, except in animal 1 , in which occurred at the posterolateral bladder wall for the left ureter. The bladder shape was similar to humans, with volume ranging from 322 to $621 \mathrm{~cm}^{3}$ and a mean of $423.70 \mathrm{~cm}^{3}$ (Figs. $6 \mathrm{c}$ and d).

Tables 1 to 4 present the anatomical parameters analyzed in this study.

\section{Variation coefficients}

The highest variation coefficients were found in the measurements of right renal volume (29.60\%), followed by bladder volume (28.94\%), left renal vein diameter at the point of compression (23.90\%), lengths of pelvic ureteral segments $(23.82 \%$ on the right and $18.33 \%$ on the left), renal volumes $(18.43 \%$ on the right and $18.23 \%$ on the left) and the width of the right caudal pole $(17.73 \%)$.

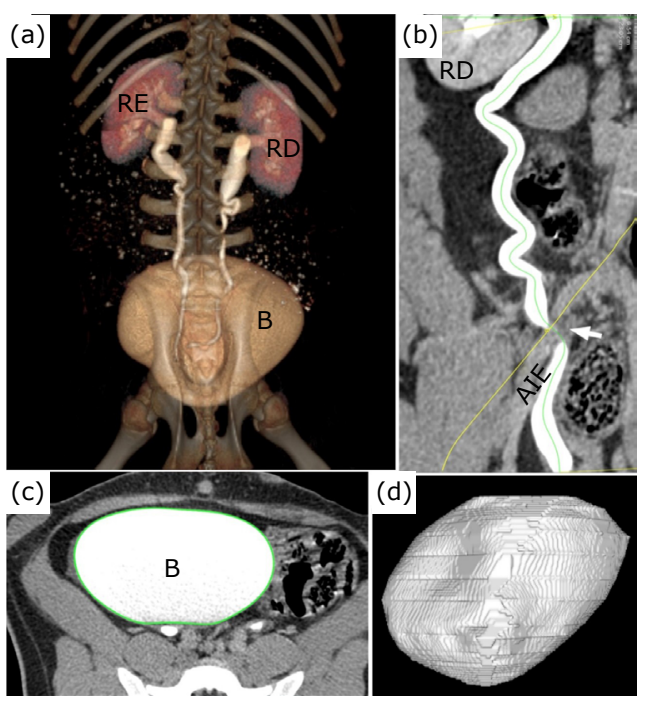

Figure 6 - (a) maximum intensity projection image (MIP); (b) ureteral length obtained through the "curved-multiplanar reformation" tool; (c) axial cut (to measure bladder volume); (d) 3D bladder reconstruction. White arrow: ureteral narrowing point over the external iliac artery; IEA: external iliac artery; RD: right kidney; RE: left kidney; B: bladder.

Table 1 - Vascular measurements.

\begin{tabular}{|c|c|c|c|c|c|c|c|}
\hline Measure $(\mathbf{m m})$ & Minimum & Maximum & Median & Mean & $\begin{array}{l}\text { Standard } \\
\text { deviation }\end{array}$ & CV\% & $\begin{array}{c}\text { p-value* } \\
\text { (right vs. left) }\end{array}$ \\
\hline Right renal artery diameter & 3.50 & 5.14 & 4.45 & 4.45 & 0.65 & 14.50 & \multirow{2}{*}{$<0.0001^{+}$} \\
\hline Left renal artery diameter & 5.08 & 5.70 & 5.10 & 5.31 & 0.30 & 5.50 & \\
\hline Right renal vein diameter & 4.90 & 6.40 & 5.78 & 5.78 & 0.67 & 11.60 & \multirow{2}{*}{$0.0336^{+}$} \\
\hline Left renal vein diameter & 5.26 & 6.35 & 6.10 & 5.82 & 0.45 & 7.80 & \\
\hline $\begin{array}{l}\text { Left renal vein diameter } \\
\text { (compression point) }\end{array}$ & 1.83 & 3.35 & 3.12 & 2.78 & 0.66 & 23.90 & Not applicable \\
\hline
\end{tabular}

*Mann-Whitney text. ${ }^{+}$Statistically significant. CV: Coefficient of variation. Source: Compiled by authors, 2019.

Table 2 - Urinary measurements.

\begin{tabular}{|c|c|c|c|c|c|c|c|}
\hline Measure (mm) & Minimum & Maximum & Median & Mean & $\begin{array}{l}\text { Standard } \\
\text { deviation }\end{array}$ & CV\% & $\begin{array}{c}\text { p-value* } \\
\text { (right vs. left) }\end{array}$ \\
\hline Total length of the right ureter & 16.06 & 23.13 & 19.20 & 19.78 & 2.83 & 14.30 & \multirow{2}{*}{$<0.0001^{+}$} \\
\hline Total length of the left ureter & 21.55 & 23.21 & 21.63 & 22.08 & 0.74 & 3.36 & \\
\hline Length of right ureter abdominal segment & 12.18 & 15.85 & 12.31 & 13.55 & 1.74 & 12.84 & \multirow{2}{*}{$<0.0001^{+}$} \\
\hline Length of left ureter abdominal segment & 13.41 & 17.52 & 15.94 & 15.75 & 1.69 & 10.71 & \\
\hline Length of right ureter pelvic segment & 3.88 & 7.28 & 6.89 & 6.16 & 1.47 & 23.82 & \multirow{2}{*}{0.9302} \\
\hline Length of left ureter pelvic segment & 5.61 & 8.22 & 5.69 & 6.42 & 1.18 & 18.33 & \\
\hline Right kidney length & 9.10 & 10.46 & 9.93 & 9.85 & 0.57 & 5.77 & \multirow{2}{*}{$<0.0001^{+}$} \\
\hline Left kidney length & 9.22 & 11.70 & 10.25 & 10.30 & 9.90 & 9.60 & \\
\hline Right cranial pole width & 5.11 & 6.45 & 6.01 & 5.82 & 0.57 & 9.80 & \multirow{2}{*}{$<0.0001^{+}$} \\
\hline Left cranial pole width & 5.65 & 6.57 & 5.88 & 6.05 & 0.40 & 6.70 & \\
\hline Right caudal pole width & 4.29 & 5.52 & 4.87 & 4.92 & 0.49 & 9.95 & \multirow{2}{*}{0.0625} \\
\hline Left caudal pole width & 4.48 & 5.16 & 4.95 & 4.85 & 0.29 & 6.00 & \\
\hline
\end{tabular}

*Mann-Whitney test. 'Statistically significant. CV: Coefficient of variation. Source: Compiled by authors, 2019. 
Table 3 - Renal hilum angle measurements.

\begin{tabular}{|c|c|c|c|c|c|c|c|}
\hline Measure (degrees) & Minimum & Maximum & Median & Mean & $\begin{array}{l}\text { Standard } \\
\text { deviation }\end{array}$ & CV\% & $\begin{array}{c}\text { p-value* } \\
\text { (right vs. left) }\end{array}$ \\
\hline Right renal hilum angle & 73.53 & 74.85 & 74.01 & 74.08 & 0.54 & 0.73 & \multirow{2}{*}{$<0.0001^{+}$} \\
\hline Left renal hilum angle & 63.87 & 70.39 & 68.82 & 67.59 & 2.88 & 4.27 & \\
\hline
\end{tabular}

*Mann-Whitney test. ${ }^{+}$Statistically significant. CV: Coefficient of variation. Source: Compiled by authors, 2019.

Table 4 - Volume measurements.

\begin{tabular}{lccccccc}
\hline Measure $\left(\mathbf{c m}^{3}\right)$ & Minimum & Maximum & Median & Mean & $\begin{array}{c}\text { Standard } \\
\text { deviation }\end{array}$ & $\begin{array}{c}\text { CV\% } \\
\text { (right vs. left) }\end{array}$ \\
\hline Right kidney volume & 79.78 & 130.50 & 122.00 & 113.70 & 20.96 & 18.43 & $<0.0001^{+}$ \\
Left kidney volume & 78.32 & 125.50 & 118.70 & 109.70 & 20.00 & 18.23 & Not applicable \\
Bladder volume & 322.00 & 621.00 & 380.0 & 423.70 & 122.60 & $28.94 \quad$ Notue \\
\hline
\end{tabular}

*Mann-Whitney test. ${ }^{+}$Statistically significant. CV: Coefficient of variation. Source: Compiled by authors, 2019.

\section{- Discussion}

Anatomical knowledge is paramount for developing experimental and training models. However, although swine are already consolidated models for these purposes, there are only few theoretical references about radiological methods for anatomical descriptions of the urinary system.

Experimental research using the porcine model has been published in the field of renal transplantation ${ }^{3}$, percutaneous nephrolitotripsy ${ }^{20}$, ureterocystostomy ${ }^{21}$, ureterorenoscopy and laparoscopic pyeloplasty ${ }^{2}$. Although different breeds are used in urological research, the review of the available literature suggests that pigs classified as "minipigs", such as Yucatan, Hanford, Göttingen and Sinclair, are not usually chosen for urological studies.

Yorkshire pigs were used in the improvement of techniques, such as robot-assisted anatrophic nephrolithotomy, reducing the morbidity during this procedure ${ }^{22}$. Animals of the same breed, with an average weight of $35 \mathrm{~kg}$, were used to evaluate the efficiency of a new retroperitoneal dialysis technique ${ }^{23}$ and animals between 3 and 4 months (weighting between 29 and $35 \mathrm{~kg}$ ) were used in experiments of ischemia and renal reperfusion ${ }^{24}$. The anatomy of the renal arteries, including their angles and branching patterns, was described by angiography in Landrace and Yorkshire pigs weighing between 50 and70 $\mathrm{kg}^{25}$.

Landrace pigs weighting between 30 and $40 \mathrm{~kg}$, the same breed used in this study, took part in research about ischemia, reperfusion and renal transplantation ${ }^{26,27}$. In another study, 3-month-old pigs (weighting about $40 \mathrm{~kg}$ ) were used to evaluate the efficacy of arterial clamping during the treatment of renal tumors by cryoablation technique ${ }^{28}$. This breed represents a good option for anatomical studies of the urinary system because it is available at an affordable cost, besides being widely used in research in the urological and endourological fields.

As well as being considered a precise and noninvasive method, CT helps to clarify the information provided by other exams, such as ultrasonography, and enhances anatomical findings. It became an important tool for urological preoperative planning ${ }^{29}$. However, information regarding the description of swine urological anatomy by CT is still limited.

\section{Swine anatomy $\times$ human}

\section{Renal vascularization}

The results showed that, as in humans, swine renal vascularization is provided by a single renal artery ${ }^{4}$. Although anatomical variations may occur from 30 to $40 \%$ in humans, being the accessory polar renal artery the most frequently observed ${ }^{30}$, such variations are rarely observed in pigs $(1.7 \%)^{4}$ and were not detected in this study.

The most common branching pattern of the renal artery in humans is the division into two polar arteries: one cranial and one caudal, each one giving two branches, one anterior and other posterior; however, variations are frequently reported ${ }^{31,32}$. In pigs, the branching pattern of the renal artery was classified by Evan et al. ${ }^{16}$ in the following types: pattern la, with the division of the renal artery into cranial and caudal polar branches, which branch into anterior and posterior segmental branches; pattern Ib, resembles la, but has a short cranial polar branch, with the emission of segmental branches directly from the renal artery; pattern II, similar to Ib, but the caudal polar branch gives a branch that irrigates the cranial pole; in pattern III there are multiple renal arteries. The most frequent pattern, as in this study, is the la, detected in 77-97\% $\%^{4,16}$. 
In both pigs and humans, renal arteries often originate from the abdominal aorta between the first and second lumbar vertebrae (L1-L2) $)^{29,33,34}$. In pigs, the numbering of the vertebrae may vary, as different breeds may differ in the number of vertebrae ${ }^{35}$. The asymmetry in the level of origin of these arteries is described in pigs and humans ${ }^{4,5}$. In this study, only one animal presented such asymmetry, being the origin of the right renal artery $8.5 \mathrm{~mm}$ caudal to the left renal artery. This asymmetry, although small, was greater than previously reported in pigs $(4.48 \mathrm{~mm})$ of different races (between 85-90 kg) and humans $(2.9 \mathrm{~mm})^{4}$.

The renal artery diameter in adult humans varies between 4.0 and $5.9 \mathrm{~mm}$ and between 5.1 and $5.4 \mathrm{~mm}$ in pigs $^{4,25,34,36}$. In pigs, this data was collected using surgical dissection, plastination and angiography in animals of different breeds between 51 and $90 \mathrm{~kg}^{4,25}$. In contrast to the literature, the present study showed a mean diameter of $4.45 \mathrm{~mm}$ on the right and $5.31 \mathrm{~mm}$ on the left, being the left renal artery diameter statistically larger than the right renal artery. For procedures in which the diameter of these vessels is an important factor, it is known that the weight of the pig has a small influence since, in these animals, the correlation between the caliber of the renal arteries and weight is disproportional, meaning there are minimal variations in the diameter between pigs of different weights ${ }^{25}$.

The renal venous drainage of the pig is also similar to humans. A single renal vein is the most observed pattern in both species ${ }^{5}$, as in the animals studied. Venous variations were rarely found in pigs, being reported additional renal veins in $2.13 \%$ after the analysis of 94 kidneys ${ }^{37}$. In humans, renal venous anomalies are more frequent, being the multiplicity of renal veins (15-30\%) more common on the right side and, less frequently (2-17\%), circumaortic and retroaortic renal veins on the left side ${ }^{38}$. The formation of renal veins, in humans and pigs, often occurs by the confluence of cranial and caudal venous tributaries, at the upper margin of second lumbar vertebrae. The number of tributaries varies between 2 and 4 in pigs and 2 and 6 in humans ${ }^{37}$.

According to the literature, in humans, the diameter of renal veins may vary between 5 and $17 \mathrm{~mm}^{37}$. A tomography study points out an average diameter of $6.98 \mathrm{~mm}$ at the right side and $6.36 \mathrm{~mm}$ at the left side in men and $6.69 \mathrm{~mm}$ at the right and $6.04 \mathrm{~mm}$ at the left side in women ${ }^{34}$. In Great Polish White pigs, between 70 and $110 \mathrm{~kg}$, the average previously described is $10.94 \mathrm{~mm}$, with variations between $4.5-15.8 \mathrm{~mm}^{37}$. In this study, an average of $5.78 \mathrm{~mm}$ was found on the right side and $5.82 \mathrm{~mm}$ on the left side, with variations between $4.90-6.40 \mathrm{~mm}$ and 5.26-6.35 mm, respectively. The caliber of the left renal vein measured at the renal hilum was statistically superior when compared to the right renal vein with the same topography. The disparity between this study and previous literature results may be related to differences regarding animal breeds and measurement techniques.

In humans, the nutcracker syndrome, which is characterized by the compression on the left renal vein between the aorta and the superior mesenteric artery, may cause lumbar pain, hematuria and proteinuria ${ }^{39}$. There was no previous report of a similar situation in pigs. This group, during the description of the swine vascular anatomy by CT angiography, in another project, detected this compressive phenomenon (data not yet published) and, in another study, conducted in humans, this compression was observed in $24.4 \%$ of adults submitted to CT examinations ${ }^{40}$. The three evaluated animals presented, on average, a 51\% diameter reduction of the left renal vein at the angle between the aorta and the anterior mesenteric artery (analogous to the human superior mesenteric artery).

\section{Kidney}

The morphometric similarities between human and swine kidneys have been widely described ${ }^{4,5,7}$. In adult humans, the average kidney length varies between 10.5 and $11.1 \mathrm{~cm}$ and discrete differences may occur in the sides $^{41,42}$. In this study, the mean renal length was $9.85 \mathrm{~cm}$ on the right and $10.30 \mathrm{~cm}$ on the left; these dimensions were close to those reported for humans by Gómez et al. ${ }^{7}$ and Arenas et al. ${ }^{5}$ who, after surgical dissection in pigs of various breeds weighing between 85 and $95 \mathrm{~kg}$, identified an average length of $12 \mathrm{~cm}$. This discrete difference compared to the results obtained may be related to the size of the animals studied and the method used for measuring ${ }^{41}$.

Both pigs and humans have a larger and more medial and cranial located renal pole in comparison to the caudal pole. In the animals studied, an average cranial pole width of $5.82 \mathrm{~cm}$ on the right and $6.05 \mathrm{~cm}$ on the left was found, and $4.92 \mathrm{~cm}$ on the right and $4.85 \mathrm{~cm}$ on the left for the caudal pole. These measurements are similar to those described by Gómez et al. ${ }^{7}$, who identified the average cranial pole width of $5.66 \mathrm{~cm}$ on the right and $5.72 \mathrm{~cm}$ on the left and caudal pole width of $5.26 \mathrm{~cm}$ on the right and $5.21 \mathrm{~cm}$ on the left. The average dimensions in humans are 6.44 and $5.49 \mathrm{~cm}$ for the cranial and caudal poles, respectively. Certainly, these similarities between the species are relevant when selecting the swine model for procedures in which renal dimensions are an important issue.

The average renal volume in humans is $94.16 \mathrm{~cm}^{3}$ on the right and $98.07 \mathrm{~cm}^{3}$ on the left and, in younger and heavier male patients, there is a tendency of larger renal volumes, especially on the left side ${ }^{43}$. Swine's kidney volume is influenced by weight, gender, age and pathologies, such as the cystic kidney disease ${ }^{44}$. No references were 
detected among pigs with weights similar to those used in this study, so a comparison could not be established. Between the surveyed pigs, the mean kidney volumes were $113.70 \mathrm{~cm}^{3}$ on the right and $109.70 \mathrm{~cm}^{3}$ on the left.

No references describing the swine hilar kidney angle were found. According to the available literature, the mean right hilar angle in humans varies between $42.47-61^{\circ}$ and $38.78-55^{\circ}$ on the left side $17,45,46$. In the present study, the renal hilar angle average was $74.08^{\circ}$ to the right and $67.59^{\circ}$ to the left.

Renal rotation anomalies were not reported in pigs. In humans, they may be associated with renal ectopy, which plays an important role in the formation of ureteropelvic obstructions. Among these alterations, the most common are the nonrotations and incomplete rotations ${ }^{17}$. Also, there is a higher incidence of renal lithiasis in patients with an insufficient rotation of the renal hilum, i.e., with a smaller renal hilum angle and pelvis arranged more anteriorly ${ }^{46}$, a fact that may be associated with the low frequency of renal lithiasis in pigs, since they present medially rotated kidneys.

\section{$\underline{\text { Ureters and bladder }}$}

Information about these structures in pigs is limited in the literature.

Human ureters cross the common iliac arteries and this vessel is used as a border between the cranial/abdominal and caudal/pelvic portions of the ureters. In pigs, ureters follow a similar path ${ }^{47}$, however, the best nomenclature for the crossed artery would be "external iliac artery", since the aorta does not bifurcate into common iliac arteries, like in humans, but instead trifurcate into two external iliac arteries and an internal iliac trunk, from which both internal iliac arteries arise.

The ureteral dimensions in humans have been studied by several authors ${ }^{47-51}$ who describe a ureteral length ranging from 25 to $30 \mathrm{~cm}$, larger when compared to the evaluated swine in this research, with a length of $19.78 \mathrm{~cm}$ on the right and $22.08 \mathrm{~cm}$ on the left.

In this study, pigs presented larger length measurements on the left side, possibly justified by the higher disposition of the left kidney compared to the right side. A review of the literature found no references about the proportion of the abdominal and pelvic segments of ureters in pigs. In humans, similar lengths were reported between these segments of ureter ${ }^{48}$, but this work demonstrated that, in pigs, the division of the ureter is uneven, with the abdominal segment corresponding to approximately $2 / 3$ of the length.

The human ureter has three points of physiological narrowing: the ureteropelvic junction, the crossing of the common iliac vessels and the ureterovesical junction ${ }^{48,52}$. The methodology used in this study allowed to verify the narrowing points of the ureteral lumen when crossing the iliac vessels in all animals and at the ureterovesical junction in two animals, both on the left. No narrowing was detected in the ureteropelvic junctions. In humans, the correlation between the points of ureteral narrowing and calculus impaction is well described ${ }^{50,53-55}$, and, likewise, the swine model can be useful for experiments and training related to lithiasis, although previous description of these narrowing has not been detected in the literature.

No previous descriptions of the mean bladder volume in pigs have been located and, certainly, such volume may vary according to the degree of bladder repletion and the method of measurement. In humans, this mean volume varies between 400 and $600 \mathrm{~mL}^{56}$ and, therefore, despite possible measurement biases, it is similar to that found in the evaluated swine, with an average volume of $423.7 \mathrm{~mL}$. Bladder manipulation during urological procedures should be careful due to the fragility of the bladder wall, which is thinner when compared to humans or other mammals ${ }^{57}$.

The urethral anatomy in male pigs makes it difficult to use this model in urological procedures involving the penis and urethra. The corkscrew shape of the tip of the penis makes it difficult to insert a urinary catheter via the urethra ${ }^{57}$. Suprapubic access with catheter placement is an alternative used for this model ${ }^{58}$. Large White, Landrace, Yorkshire and Duroc females, weighing 30-40 kg, were successfully submitted to ureteral catheterization, although difficulty was reported during the procedure ${ }^{59,60}$.

Among the limitations of this research is the fact that only three animals were studied, all of the same sex, and that the definition and heterogeneity of the images did not allow the measurement of the cortical thickness, the evaluation of the renal pelvis and the description of the pyelocaliceal system.

\section{- Conclusions}

Based on the obtained results and comparisons made to the human anatomy, it was found that the pig is particularly useful for the following models of procedures related to the urinary system: total and partial nephrectomy, intrarenal procedures (such as biopsy and nephrolithotomy), kidney transplantation and nephrolithotripsy.

By providing these compared anatomic descriptions, the planning of preclinical trials, basic research and improving surgical training using porcine models in urology may be facilitated.

\section{- References}

1. Fagundes DJ, Taha MO. Modelo animal de doença: critérios de escolha e espécies de animais de uso corrente. Acta Cir Bras. 2004;19(1):59-65. https://doi.org/10.1590/S010286502004000100010 
Image-guided study of swine anatomy as a tool for urologic surgery research and training Smit JHA et al.

2. Aydin A, Raison N, Khan MS, Dasgupta P, Ahmed K. Simulation-based training and assessment in urological surgery. Nat Rev Urol. 2016;13(9):503-19. https://doi. org/10.1038/nrurol.2016.147

3. Golriz M, Fonouni $H$, Nickkholgh A, Hafezi M, Garoussi C, Mehrabi A. Pig Kidney Transplantation: An Up-To-Date Guideline. Eur Surg Res. 2012;49(3-4):121-9. https://doi. org/10.1159/000343132

4. Gómez FA, Ballesteros LE, Estupiñan HY. Morphological Characterization of the Renal Arteries in the Pig: Comparative Analysis with the Human. Int J Morphol. 2017;35(1):319-24. https://doi.org/10.4067/S071795022017000100050

5. Arenas F, Rincón J, Álvarez JC, Gómez FA, Cortés LS. Contribution to the Anatomical Study of Urinary System in Pigs. Spei Domus. 2015;11(22):19-24. https://doi. org/10.16925/sp.v11i22.1153

6. Pereira-Sampaio MA, Henry RW, Favorito LA, Sampaio FJB. Cranial Pole Nephrectomy in the Pig Model: Anatomic Analysis of Arterial Injuries in Tridimensional Endocasts. J Endourol. 2012;26(6):716-21. https://doi.org/10.1089/ end.2011.0489

7. Gómez FA, Ballesteros LE, Estupiñán HY. Anatomical study of the renal excretory system in pigs. A review of its characteristics as compared to its human counterpart. Folia Morphol. 2017;76(2):262-8. https://doi.org/10.5603/ FM.a2016.0065

8. Bhullar JS, Scott R, Patel M, Mittal VK. Kidney Access Device. JSLS. 2014;18(4):e2014.00219. https://doi.org/10.4293/ JSLS.2014.00219

9. Hammond L, Ketchum J, Schwartz BF. A new approach to urology training: a laboratory model for percutaneous nephrolithotomy. J Urol. 2004;172(5):1950-2. https://doi. org/10.1097/01.ju.0000140279.15186.20

10. Noureldin YA, Andonian S. Simulation for Percutaneous Renal Access: Where Are We? J Endourol. 2017;31(1):S109. https://doi.org/10.1089/end.2016.0587

11. Caldas PFO, Rocha LCA, Oliveira MT, Ataíde MW, Spagnolo JD, Feranti JPS, et al. Laparoscopic ureterocalicostomy in pigs - experimental study. Ciênc Rural. 2015;45(7):1262-7. https://doi.org/10.1590/0103-8478cr20140384

12. Cooper DKC, Iwase H, Wang L, Yamamoto T, Li Q, Li J, et al. Bringing Home The Bacon: Update on The State of Kidney Xenotransplantation. Blood Purif. 2018;45(1-3):254-9. https://doi.org/10.1159/000485163

13. Pereira-Sampaio MA, Favorito LA, Sampaio FJB. Pig kidney: anatomical relationships between the intrarenal arteries and the kidney collecting system. Applied study for urological research and surgical training. J Urol. 2004;172(5):2077-81. https://doi.org/10.1097/01.ju.0000138085.19352.b5

14. Wolf Junior JS, Humphrey PA, Rayala HJ, Gardner SM, Mackey RB, Clayman RV. Comparative ureteral microanatomy. J Endourol. 1996;10(6):527-31. https:// doi.org/10.1089/end.1996.10.527

15. Ragionieri L, Ravanetti F, Gazza F, Botti M, Ivanovska A, Cacchioli A. Morphological analysis of the urethral muscle of the male pig with relevance to urinary continence and micturition. J Anat. 2016;228(3):511-9. https://doi. org/10.1111/joa.12415
16. Evan AP, Connors BA, Lingeman JE, Blomgren $\mathrm{P}$, Willis LR. Branching patterns of the renal artery of the pig. Anat Rec. 1996;246(2):217-23. https://doi.org/10.1002/ (SICI)1097-0185(199610)246:2\%3C217::AIDAR8\%3E3.0.CO;2-Y

17. Sakate M, Sakate ATY, Yamashita S, Teixeira AS, Barbosa L, Correia LA. Tomografia computadorizada de abdome normal: estudo retrospectivo das angulações dos hilos renais. Radiol Bras. 2009;42(1):27-9. https://doi. org/10.1590/S0100-39842009000100007

18. Kim SH. Doppler US and CT Diagnosis of Nutcracker syndrome. Korean J Radiol. 2019;20(12):1627-37. https:// doi.org/10.3348/kjr.2019.0084

19. Miranda CMNR, Maranhão CPM, Santos CJJ, Padilha IG, Farias LPG, Rocha MS. Bosniak classification of renal cystic lesions according to multidetector computed tomography findings. Radiol Bras. 2014;47(2):115-21. https://doi. org/10.1590/S0100-39842014000200015

20. Xing Y, Chen TT, Simmons WN, Sankin G, Cocks FH, Lipkin $\mathrm{ME}$, et al. Comparison of Broad vs Narrow Focal Width Lithotripter Fields. J Endourol. 2017;31(5):502-9. https:// doi.org/10.1089/end.2016.0560

21. Hoffman MS, Spiess PE. Simulated management of urinary tract injury during robotic pelvic surgery utilizing the porcine model. J Robot Surg. 2019;13(2):289-92. https:// doi.org/10.1007/s11701-018-0852-z

22. Sood A, Hemal AK, Assimos DG, Peabody JO, Menon M, Ghani KR. Robotic anatrophic nephrolithotomy utilizing near-infrared fluorescence image-guidance: Idea, Development, Exploration, Assessment, and Longterm Monitoring (IDEAL) Stage 0 Animal Model Study. Urology. 2016;94:117-22. https://doi.org/10.1016/j. urology.2016.04.051

23. Okhunov Z, Yoon R, Lanzac AP, Sgroi M, Lau WL, Del Junco $M$, et al. Development and evaluation of a retroperitoneal dialysis porcine model. Clin Nephrol. 2016;86(2):70-7. https://doi.org/10.5414/CN108775

24. Sincos APWB, Mazzeo A, Sincos IR, Coelho Neto F, Wolosker $N$, Aun R, et al. Duplex scan and histologic assessment of acute renal injury in a kidney-kidney crosstalk swine experimental model. J Vasc Surg. 2018;68(2):588-95. https://doi.org/10.1016/j.jvs.2017.06.118

25. Sakaoka A, Koshimizu M, Nakamura S, Matsumura K. Quantitative angiographic anatomy of the renal arteries and adjacent aorta in the swine for preclinical studies of intravascular catheterization devices. Exp Anim. 2018;67(2):291-9. https://doi.org/10.1538/ expanim.17-0125

26. Golriz M, Fonouni $H$, Kuttymuratov G, Esmaeilzadeh $M$, Rad MT, Jarahian $P$, et al. Influence of a modified preservation solution in kidney transplantation: a comparative experimental study in a porcine model. Asian J Surg. 2017;40(2):106-15. https://doi.org/10.1016/j. asjsur.2015.07.001

27. Sedigh A, Nordling S, Carlsson F, Larsson E, Norlin B, Lübenow N, et al. Perfusion of Porcine Kidneys with Macromolecular Heparin Reduces Early Ischemia Reperfusion injury. Transplantation. 2019;103(2):420-7. https://doi.org/10.1097/TP.0000000000002469 
28. Nonboe LL, Nielsen TK, Høyer S, Graumann O, Frøkiær J, Borre M. Arterial Clamping Increases Central Renal Cryoablation Efficacy: An Animal Study. Technol Cancer Res Treat. 2017;16(4):414-20. https://doi. org/10.1177/1533034616663365

29. Vernuccio F, Gondalia R, Churchill S, Bashir MR, Marin D. CT evaluation of the renal donor and recipient. Abdom Radiol. 2018;43(10):2574-88. https://doi.org/10.1007/s00261-0181508-1

30. Çınar C, Türkvatan A. Prevalence of renal vascular variations: Evaluation with MDCT angiography. Diagn Interv Imaging. 2016;97(9):891-7. https://doi.org/10.1016/j. diii.2016.04.001

31. Shoja MM, Tubbs RS, Shakeri A, Loukas M, Ardalan MR, Khosroshahi HT, Oakes WJ. Peri-hilar branching patterns and morphologies of the renal artery: a review and anatomical study. Surg Radiol Anat. 2008;30(5):375-82. https://doi.org/10.1007/s00276-008-0342-5

32. Dăescu E, Zăhoi DE, Motoc A, Alexa A, Baderca F, Enache A. Morphological variability of the renal artery branching pattern: a brief review and an anatomical study. Rom J Morphol Embryol. 2012;53(2):287-91.

33. Cases C, García-Zoghby L, Manzorro P, Valderrama-Canales $\mathrm{FJ}$, Muñoz $M$, Vidal $M$, et al. Anatomical variations of the renal arteries: cadaveric and radiologic study, review of the literature, and proposal of a new classification of clinical interest. Ann Anat. 2017;211:61-8. https://doi. org/10.1016/j.aanat.2017.01.012

34. Ferhatoglu MF, Atli E, Gürkan A, Kebudi A. Vascular variations of the kidney, retrospective analysis of computed tomography images of ninety-one laparoscopic donor nephrectomies, and comparison of computed tomography images with perioperative findings. Folia Morphol (Warsz). 2020;79(4):786-92. https://doi.org/10.5603/FM.a2019.0135

35. Rohrer GA, Nonneman DJ, Wiedmann RT, Schneider JF. A study of vertebra number in pigs confirms the association of vertnin and reveals additional QTL. BMC Genet. 2015;16:129. https://doi.org/10.1186/s12863-015-0286-9

36. Gulas E, Wysiadecki G, Szymański J, Majos A, Stefańczyk L, Topol M, et al. Morphological and clinical aspects of the occurrence of accessory (multiple) renal arteries. Arch Med Sci. 2018;14(2):442-53. https://doi.org/10.5114/ aoms.2015.55203

37. Szymański J, Polguj M, Topol M, Oszukowski P. Anatomy of renal veins in swine. Med Weter. 2015;71(12):773-7.

38. Zhu J, Zhang L, Yang Z, Zhou H, Tang G. Classification of the renal vein variations: a study with multidetector computed tomography. Surg Radiol Anat. 2015;37(6):667-75. https:// doi.org/10.1007/s00276-014-1403-6

39. Vianello FA, Mazzoni MBM, Peeters GGAM, Fossali EF, Camozzi P, Bianchetti MG, et al. Micro- and macroscopic hematuria caused by renal vein entrapment: systematic review of the literature. Pediatr Nephrol. 2016;31(12):17584. https://doi.org/10.1007/s00467-015-3045-2

40. Góes Junior AMO, Araújo RS, Furlaneto IP, Vieira WB. Compressões das veias renal e ilíaca comum esquerdas em tomografias computadorizadas: com que frequência são detectadas? J Vasc Bras. 2020;19:e20190121. https://doi. org/10.1590/1677-5449.190121
41. Karami M, Rahimi F, Tajadini M. The evaluation and comparison of kidney length obtained from axial cuts in spiral CT scan with its true length. Adv Biomed Res. 2015;4:19. https://doi.org/10.4103/22779175.149850

42. Glodny B, Unterholzner V, Taferner B, Hofmann KJ, Rehder P, Strasak A, et al. Normal kidney size and its influencing factors - a 64-slice MDCT study of 1.040 asymptomatic patients. BMC Urol. 2009;9:19. https://doi. org/10.1186/1471-2490-9-19

43. Talhar SS, Waghmare JE, Paul L, Kale S, Shende MR. Computed Tomographic Estimation of Relationship Between Renal Volume and Body Weight of an Individual. J Clin Diagn Res. 2017;11(6):AC04-8. https://doi. org/10.7860/JCDR/2017/25275.10010

44. Grantham JJ, Torres VE. The importance of total kidney volume in evaluating progression of polycystic kidney disease. Nat Rev Nephrol. 2016;12(11):667-77. https:// doi.org/10.1038/nrneph.2016.135

45. Palma LD, Rossi M. Advances in radiological anatomy of the kidney. Br J Radiol. 1982;55(654):404-12. https://doi. org/10.1259/0007-1285-55-654-404

46. Sanal B, Korkmaz M, Can F, Aras B, Buyukkaya A. Do the variations in renal pelvic angles play a role in the formation of renal stone? A computed tomography study. Ren Fail. 2015;37(9):1448-51. https://doi.org/10.3109/0 886022X.2015.1074491

47. Petsepe DC, Kourkoulis SK, Papadodima SA, Sokolis DP. Regional and age-dependent residual strains, curvature, and dimensions of the human ureter. Proc Inst Mech Eng H. 2018;232(2):149-62. https://doi. org/10.1177/0954411917750192

48. Kulkarni R. Anatomy of the human ureter. Ureteric Stenting. Hoboken: John Wiley \& Sons, 2017. https://doi. org/10.1002/9781119085713.ch1

49. Fröber R. Surgical anatomy of the ureter. BJU Int. 2007;100(4):949-65. https://doi.org/10.1111/j.1464410X.2007.07207.x

50. Potenta SE, D'Agostino R, Sternberg KM, Tatsumi K, Perusse K. CT Urography for Evaluation of the Ureter. RadioGraphics. 2015;35(3):709-26. https://doi. org/10.1148/rg.2015140209

51. Wong SL, Hamid HA. Observation of Ureteric Diameter in Negative Intravenous Urogram in Hospital Universiti Kebangsaan Malaysia. Malays J Med Sci. 2010;17(2):4-9.

52. Selçuk I, Ersak B, Tatar I, Güngör T, Huri E. Basic clinical retroperitoneal anatomy for pelvic surgeons. Turk J Obstet Gynecol. 2018;15(4):259-69. https://doi. org/10.4274/tjod.88614

53. Ordon M, Schuler TD, Ghiculete D, Pace KT, Honey RJD. Stones Lodge at Three Sites of Anatomic Narrowing in the Ureter: Clinical Fact or Fiction? J Endourol. 2013;27(3):270-6. https://doi.org/10.1089/ end.2012.0201

54. El-Barky E, Ali Y, Sahsah M, Terra AA, Kehinde EO. Site of impaction of ureteric calculi requiring surgical intervention. Urolithiasis. 2014;42(1):67-73. https://doi. org/10.1007/s00240-013-0605-4 
55. Moon YJ, Kim H-W, Kim JB, Kim HJ, Chang Y-S. Distribution of ureteral stones and factors affecting their location and expulsion in patients with renal colic. Korean J Urol. 2015;56(10):717-21. https://doi.org/10.4111/kju.2015.56.10.717

56. Ozturk NK, Kavakli AS. Use of bladder volume measurement assessed with ultrasound to predict postoperative urinary retention. North Clin Istanb. 2017;3(3):209-16. https:// doi.org/10.14744/nci.2016.03164

57. Swindle MM, Makin A, Herron AJ, Clubb Junior FJ, Frazier KS. Swine as Models in Biomedical Research and Toxicology Testing. Vet Pathol. 2012;49(2):344-56. https://doi. org/10.1177/0300985811402846
58. Holliman CJ, Kenfield K, Nutter E, Saffle JR, Warden GD. Technique for acute suprapubic catheterization of urinary bladder in the pig. Am J Vet Res. 1982;43(6):1056-7.

59. Nielsen TK, Petersen NA, Staerk K, Grønnemose RB, Palarasah Y, Nielsen LF, et al. A Porcine Model for Urinary Tract Infection. Front Microbiol. 2019;10:2564. https:// doi.org/10.3389/fmicb.2019.02564

60. Musk GC, Zwierzchoniewska M, He B. Catheterization of the urethra in female pigs. Lab Anim. 2015;49(4):345-8. https://doi.org/10.1177/0023677215587637

\section{Correspondence:}

Adenauer Marinho de Oliveira Góes Junior

Rua Domingos Marreiros, 307/802

66055-974 Belém - PA Brasil

Tel.: (55 91)98127-9656

adenauerjunior@gmail.com

Received: Aug 13, 2020

Review: Oct 10, 2020

Accepted: Nov 11, 2020
Conflict of interest: none

Financial source: none

This is an Open Access article distributed under the terms of the Creative Commons Attribution License, which permits unrestricted use, distribution, and reproduction in any medium, provided the original work is properly cited.

${ }^{1}$ Research performed at Centro Universitário do Estado do Pará (CESUPA), Grupo de Pesquisa Experimental (GPE), Belém (PA), Brazil. 